\title{
APROVEITAMENTO DE ÁGUA PLUVIAL PARA FINS NÃO POTÁVEIS RESIDENCIAIS EM RIO BRANCO - AC
}

\author{
Wilians Montefusco da Cruz \\ Mestre em Processos Construtivos e Saneamento Urbano / Universidade Federal do Pará \\ montefusco25@hotmail.com
}

\section{Claudio José Cavalcante Blanco}

Doutor em Sciences de l'eau / Université du Québec - INRS-ETE, INRS-ETE, Canadá blanco@ufpa.br

\section{RESUMO}

A captação pluvial desponta como alternativa eficiente de aproveitamento de água, possibilitando a ampliação da oferta de água potável pelo poder público à população com o uso da água de chuva, não tratada, para fins menos nobres; e, ainda, reduzindo o escoamento superficial, minimizando os transtornos com enchentes. Assim, o trabalho avaliou o aproveitamento de água pluvial para fins não potáveis, levando em consideração parâmetros como: precipitação de projeto, área de captação, demanda de água, bem como dimensionamento de calhas, condutos e reservatório; e avaliou a viabilidade financeira do projeto, que foi quantificada através do tempo de retorno do investimento. $\mathrm{O}$ tempo de retorno resultou em 27,1 anos, tornando a instalação inviável financeiramente, mesmo apresentando uma redução mensal de aproximadamente $30 \%$ no consumo de água potável. Entende-se assim, que a amortização do investimento em sistemas de aproveitamento de água pluvial ocorre de forma lenta, sobretudo devido ao baixo custo da água potável em Rio Branco. Por outro lado, o sistema proporciona uma economia de $7,93 \mathrm{~m}^{3}$ de água tratada mensalmente.

Palavras-chave: Aproveitamento de água pluvial, Captação de água de chuva, Uso racional da água

\begin{abstract}
Rainwater harvesting emerges as an efficient alternative to water use, making it possible to increase the supply of drinking water by the public power to the population with the use of untreated rainwater for less noble purposes; reducing runoff, minimizing flooding disorders. Thus, the study evaluated the utilization of rainwater for non-potable purposes, taking into account parameters such as: precipitation of project, catchment area, water demand, as well as sizing of ducts, conduits and reservoir and assessed the financial viability of the project, which was quantified through the pay back. The pay back resulted in 27.1 years, making the project financially unfeasible, even presenting a monthly reduction of approximately $30 \%$ in drinking water consumption. It is understood that the amortization of investment in rainwater harvesting systems occurs slowly, mainly due to the low cost of drinking water in Rio Branco. On the other hand, the system provides a saving of $7.93 \mathrm{~m}^{3}$ of treated water monthly.
\end{abstract}

Keywords: Rainwater harvesting, Capture of rainwater, Rational use of water

Persp. Online: exatas \& eng., Campos dos Goytacazes, 17 (07) 12 - 24 - 2017

seer.perspectivasonline.com.br 


\section{INTRODUÇÃO}

Observa-se que a água destinada ao consumo humano pode ter dois fins distintos, por exemplo, parte da água que abastece uma residência é utilizada para higiene pessoal, para beber e cozinhar alimentos, sendo estes usos designados como usos potáveis. A outra parcela da mesma água que chega às residências é destinada aos usos não potáveis, como lavagem de roupas, carros e calçadas, irrigação de jardins e descarga de vasos sanitários (ANNECCHINI, 2005). Estudos mostram que o consumo de água destinado aos usos não potáveis em uma residência varia de $30 \%$ a $40 \%$ do total de água consumida (KÖNIG, 2001). Esta parcela de água poderia ser atendida por fontes alternativas, visando à conservação da água e gerando uma economia para o consumidor. Como alternativas, tem-se a captação e utilização de água da chuva, de águas salinas e a reutilização ou reuso de água. A alternativa de aproveitamento de água da chuva apresenta muitos benefícios, além de ser simples e de baixo custo, podendo reduzir a demanda de água potável em uma cidade, aliviar o estresse de água na região, reduzir o volume e escoamento superficial, evitando inundações, conforme visto nos estudos de Eroksuz e Rahman (2010); Ghimire e Jhonston (2013); Campisano et al. (2014); e Zhu et al. (2004).

Assim, o presente trabalho buscou analisar a utilização da água de chuva na cidade de Rio Branco-AC e estudou o seu potencial quantitativo de utilização em áreas urbanas, com vistas ao seu aproveitamento como fonte de abastecimento para fins não potáveis em edificações unifamiliar, dimensionando e levantando custos, estimando o tempo de retorno dos investimentos empregados na implantação do sistema, bem como verificando a viabilidade financeira.

\section{METODOLOGIA}

A metodologia avaliou precipitação de projeto, demanda de água mensal, área de captação, volume de água captada, dimensionamento do reservatório e calhas; número de condutos verticais, custos de capital e serviços; e o tempo de retorno do investimento, tendo como objeto de estudo os dados disponíveis de uma residência unifamiliar construída no ano de 2013 na cidade de Rio BrancoAC. A casa é dotada de 2 (dois) quartos e 1 (uma) suíte, possuindo uma área total construída de 202,46 $\mathrm{m}^{2}$ e abriga, atualmente, 05 (cinco) pessoas. A residência está localizada nas seguintes coordenadas geográficas: latitude $9^{\circ} 57^{\prime} 29.20^{\prime \prime} \mathrm{S}$ e longitude $67^{\circ} 48^{\prime} 43.86^{\prime} \mathrm{O}$. Na Figura 1, pode-se observar a localização da residência.

Persp. Online: exatas \& eng., Campos dos Goytacazes, 17 (07) 12 - 24 - 2017 seer.perspectivasonline.com.br 


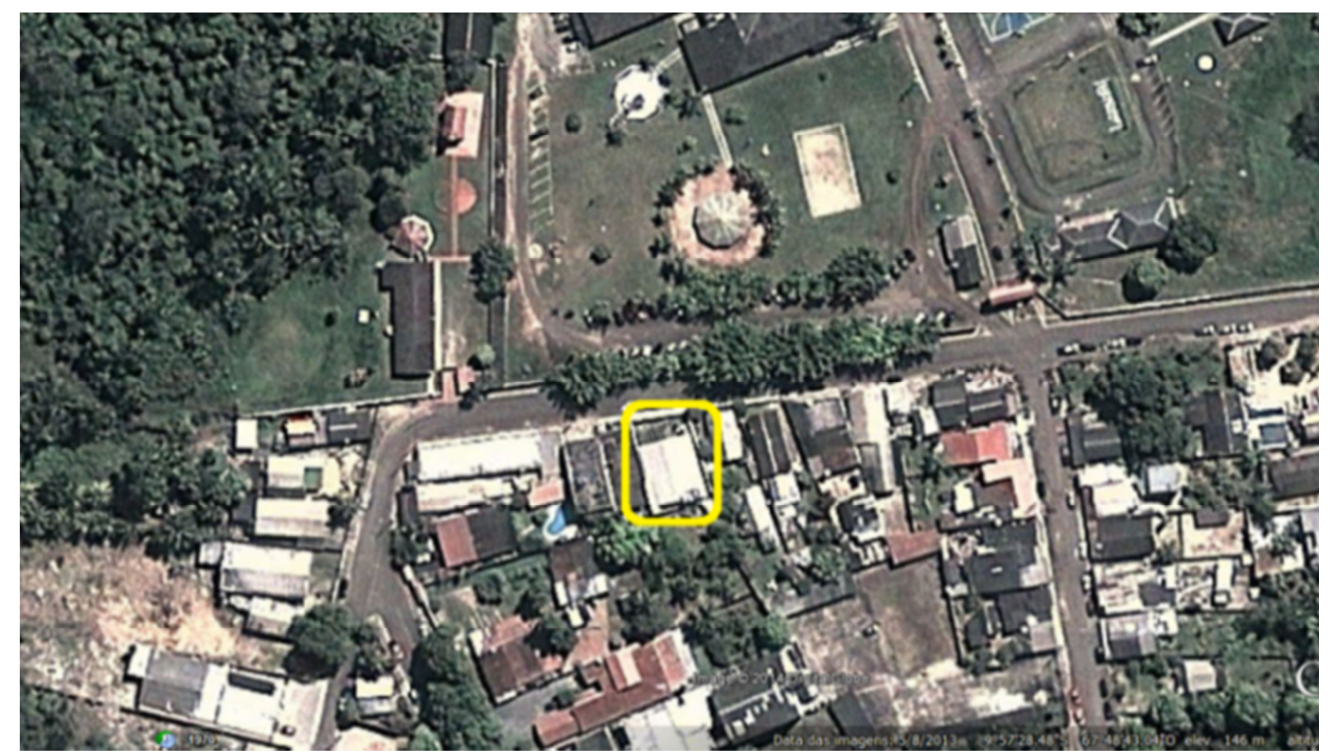

Figura 1: Localização da unidade residencial. Fonte: Adaptado de Google, 2014.

\subsection{Precipitação de projeto}

A precipitação de projeto foi definida como a menor entre os valores da chuva média anual do ano de menor pluviosidade; e a chuva média das precipitações mínimas de cada mês do período analisado. Assim, foi elaborado um pluviograma (Figura 2) para auxiliar na determinação dessa precipitação, com dados de uma série histórica mensal, tendo um período de 43 anos (1970-2012), disponibilizados pela Coordenadoria Geral de Defesa Civil do Acre - CEDEC. Através desses dados, também foi elaborada a Tabela 1 para determinação da precipitação de projeto.

Tabela 1: Lâminas de chuva mínimas, médias e máximas mensais de Rio Branco

\begin{tabular}{|c|c|c|c|c|c|c|c|c|c|c|c|c|}
\hline Item & JAN & FEV & MAR & ABR & MAI & JUN & JUL & AGO & SET & OUT & NOV & DEZ \\
\hline Mínima & 140,0 & 141,2 & 87,9 & 44,2 & 19,0 & 0,0 & 0,0 & 0,0 & 9,6 & 49,2 & 91,5 & 126,1 \\
\hline Média & 278,2 & 287,7 & 256,7 & 186,8 & 97,2 & 30,6 & 36,1 & 46,3 & 89,3 & 153,5 & 206,7 & 249,2 \\
\hline Máxima & 461,6 & 465,1 & 475,2 & 434,0 & 235,0 & 89,7 & 153,2 & 131,4 & 236,4 & 295,4 & 352,3 & 436,9 \\
\hline
\end{tabular}

\subsection{Demanda de água mensal para fins não potáveis}

Para se calcular o consumo mensal de água para fins não potáveis, faz-se necessário conhecer as características da unidade residencial, assim, para o estudo de caso em tela, tem-se:

- Tipo de edificação: Residência Unifamiliar;

- Usos para a água captada: Descarga de bacias sanitárias, lavagem de roupas, automóveis, garagem e rega de jardim;

- Quantidade de pessoas na residência: 05 (cinco) pessoas;

- Quantidade de Automóveis e quantidade de lavagens: 02 (dois) veículos de passeio, 4 lavagens por veículo por mês;

- Área do piso da garagem e quantidade de lavagens: $28,61 \mathrm{~m}^{2}$ de piso, 8 lavagens por mês;

- Área do jardim e quantidade de regas: $177,04 \mathrm{~m}^{2}$ de jardim, 8 regas por mês.

Persp. Online: exatas \& eng., Campos dos Goytacazes, 17 (07) 12 - 24 - 2017

seer.perspectivasonline.com.br 


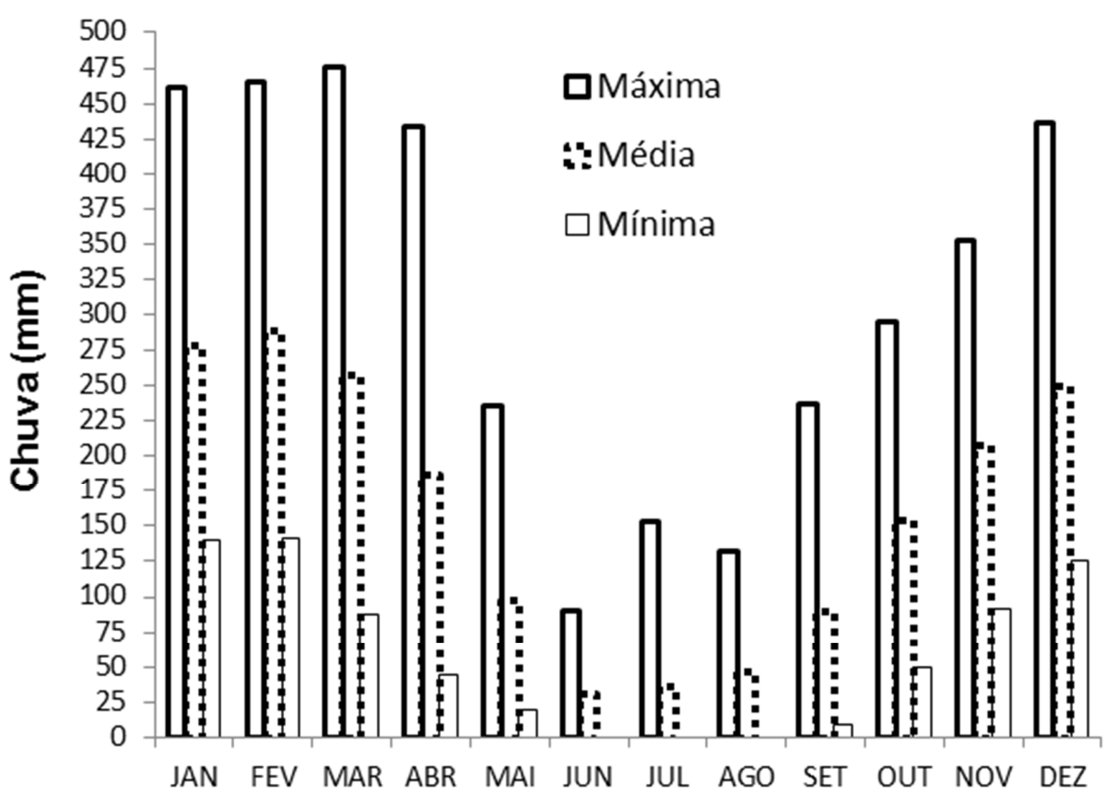

Figura 2: Pluviograma mensal para o período entre 1970-2012 de Rio Branco-AC

Para as atividades descritas anteriormente, considerou-se os seguintes volumes consumidos: com lavagem de roupas, $15 \mathrm{~L} /$ pessoa/dia; com aparelhos sanitários, $10 \mathrm{~L} /$ pessoa/dia (FEITOSA e FILHO, 2013); com veículos, $200 \mathrm{~L} /$ lavagem; com lavagem de pisos $2 \mathrm{~L} / \mathrm{m}^{2}$; com rega de jardins, 15 $\mathrm{L} / \mathrm{m}^{2}$ (AZEVEDO NETTO et al., 1998). Esses valores foram aplicados à Equação 1 para cálculo da demanda mensal de água da chuva.

$$
\mathrm{DAM}=[\mathrm{NPE} .(\mathrm{VDS}+\mathrm{VLR}) .30]+\mathrm{VLC} . \mathrm{NLC}+\mathrm{VLP} . \mathrm{NLP}+\mathrm{VRJ} . \mathrm{NRJ}
$$

Sendo: DAM - Demanda de Água Mensal (L/mês); NPE - Número de Pessoas da Edificação (); VDS - Volume Descarga Sanitária (L/pessoa/dia); VLR - Volume Lavagem de Roupa (L/pessoa/dia); VLC - Volume Lavagem de Carro (L/lavagem); NLC - Número de Lavagem de Carro (lavagem/mês); VLP - Volume Lavagem de Piso (L/lavagem); NLP - Número de Lavagem de Piso (lavagem/mês); VRJ - Volume Rega de Jardim (L/rega); e NRJ - Número de Rega do Jardim (rega/mês).

\section{3. Área de captação e volume de água captada}

A área de captação foi determinada conforme a Equação (2), estipulada por ABNT (1989), e os dados extraídos do projeto arquitetônico residencial.

$$
\mathrm{A}=[(\mathrm{a}+-) \times \mathrm{b}] \times 2
$$

Sendo: A - área de captação $\left(\mathrm{m}^{2}\right)$; a - comprimento frontal de meia água $(\mathrm{m})$; b - comprimento lateral do telhado (m); e h - altura do desnível do telhado (m).

Persp. Online: exatas \& eng., Campos dos Goytacazes, 17 (07) 12 - 24 - 2017

seer.perspectivasonline.com.br 
De acordo com ABNT (2007), o volume de água de chuva aproveitável depende do coeficiente de escoamento superficial da cobertura, bem como da eficiência do sistema de descarte do escoamento inicial, sendo calculado pela Equação 3.

$\mathrm{V}=$ P. A. C. $\eta$

Sendo: V - volume anual, mensal ou diário de água de chuva aproveitável $\left(\mathrm{m}^{3}\right)$; $\mathrm{P}$ precipitação média anual, mensal ou diária $(\mathrm{mm})$; A - área de captação $\left(\mathrm{m}^{2}\right) ; \mathrm{C}$ - coeficiente de escoamento superficial da cobertura (-); e $\eta$ - fator de captação (-).

O fator de captação é a eficiência do sistema, levando em conta o dispositivo de descarte de sólidos e desvio de escoamento inicial, caso este último seja utilizado. Segundo Tomaz (2009), a eficiência do first flush ou do descarte de filtros e telas variam de 0,50 a 0,90 . Um valor prático quando não se têm dados é adotar: C x $\eta=0,80$ (MUNDT et al., 2013).

\subsection{Componentes hidráulicos do sistema}

O dimensionamento da calha foi determinado conforme Azevedo Netto et al. (1998), que definem para um telhado de largura igual a $7 \mathrm{~m}$, como o telhado da edificação analisada, uma largura de calha igual a $0,2 \mathrm{~m}$, sendo a altura, $\mathrm{H}$, da calha igual à metade da largura, $\mathrm{L}$. Para melhor segurança quanto ao escoamento, os condutos verticais devem ser dimensionados, levando em consideração o valor da chuva crítica. Botelho e Ribeiro Jr. (1998) citam um método prático que fornece o diâmetro dos condutos verticais para as chuvas críticas de $120 \mathrm{~mm} / \mathrm{h}$ e $150 \mathrm{~mm} / \mathrm{h}$. Devido à alta pluviosidade da região amazônica, adotou-se o valor de $150 \mathrm{~mm} / \mathrm{h}$, definindo um conduto com diâmetro de $100 \mathrm{~mm}$, dando vazão ao escoamento proporcionado por $90,00 \mathrm{~m}^{2}$ de telhado. Desta forma, pode-se calcular a quantidade de condutos verticais que serão utilizados para dar vazão à chuva que se precipita no telhado através da Equação 4.

$$
\mathrm{NCV}=\mathrm{A} / \mathrm{AMT}
$$

(4)

Sendo: NCV - número de condutos verticais (-); A - área de captação $\left(\mathrm{m}^{2}\right)$; e AMT - área máxima de telhado $\left(\mathrm{m}^{2}\right)$.

ABNT (2007) define que o dimensionamento da capacidade do reservatório de água pluvial pode ser feito com qualquer método, a critério do projetista. No entanto, seis métodos de cálculo são sugeridos: método de Rippl, método da Simulação, método Azevedo Netto, método Prático Alemão, método Prático Inglês e método Prático Australiano. Neste trabalho, foi utilizado o Método de Rippl. $\mathrm{O}$ dimensionamento por esse método inicia-se pelos cálculos do volume de água pluvial no reservatório no tempo $t$ e do volume de água pluvial no tempo $t$, expressos pelas Equações 5 e 6 respectivamente:

$\mathrm{S}_{(\mathrm{t})}=\mathrm{D}_{(\mathrm{t})}-\mathrm{Q}_{(\mathrm{t})}$

$\mathrm{Q}_{(\mathrm{t})}=\mathrm{C} \times \mathrm{P} \times \mathrm{A}$

(6)

Persp. Online: exatas \& eng., Campos dos Goytacazes, 17 (07) 12 - 24 - 2017

seer.perspectivasonline.com.br 
Sendo: S - volume de água pluvial no reservatório (L); Q - volume de chuva aproveitável (L); D - demanda ou consumo de água pluvial (L); C - coeficiente de escoamento superficial (-); P precipitação média da chuva $(\mathrm{mm})$; A - área de captação em projeção no terreno $\left(\mathrm{m}^{2}\right)$; e $\mathrm{t}$ - tempo.

A capacidade do reservatório de água pluvial é calculada por meio da Equação 7.

$\mathrm{V}=\Sigma \mathrm{S}_{(\mathrm{t})}$, somente para valores $\mathrm{S}_{(\mathrm{t})}>0$

(7)

Sendo: $\mathrm{V}$ - volume do reservatório (L), $\operatorname{com} \Sigma \mathrm{D}_{(\mathrm{t})}<\Sigma \mathrm{Q}_{(\mathrm{t})}$.

Para o caso analisado, o valor de $C$ considerado foi aquele para telhados perfeitos sem fugas com valor entre 0,70 e 0,95 (FENDRICH e OLIYNIK, 2002), já que se trata de uma residência seminova.

\subsection{Custo e tempo de retorno do sistema}

O custo do sistema foi determinado com base na Equação 8 .

$\mathrm{CS}=\mathrm{CR}+\mathrm{CMH}+\mathrm{CME}+\mathrm{CMO}$

(8)

Sendo: CS - Custo do sistema (R\$); CR - Custo do Reservatório (R\$); CMH - Custo do Material Hidráulico (R\$); CME - Custo do Material Elétrico (R\$); e CMO - Custo da Mão de Obra $(\mathrm{R} \$)$.

Para se estabelecer um critério econômico para o sistema de água de chuva, optou-se pela determinação do tempo de retorno do investimento, o qual define o tempo necessário para que o capital investido seja recuperado pelo rendimento adquirido. Matematicamente definido pela razão entre o capital investido e o rendimento. Sendo, o capital investido $C S$; e o rendimento a economia gerada com o sistema $E S$ (Eq. 9).

$\mathrm{TR}=\mathrm{CS} / \mathrm{ES}$

(9)

Sendo: TR - Tempo de Retorno do Investimento (anos); CS - Custo do sistema (R\$); e ES Economia do Sistema (R\$).

Na Figura 3, é apresentada a conta mensal de serviços de água e/ou esgoto de Rio Branco. Nesse caso, a Economia do Sistema (ES) foi baseada no valor de $1,99 \mathrm{R} \$ / \mathrm{m}^{3}$, sendo esse valor multiplicado pelo tempo de operação do sistema e pela DAM. Os custos do sistema foram determinados com base na Equação 8, desconsiderando os custos com material elétrico (CME), tendo em vista que no sistema analisado não foi utilizado conjunto moto-bomba, pois foi aproveitado o desnível entre o telhado e os pontos de utilização da água da chuva captada. Como o custo do reservatório varia com o NPE, foi determinada uma curva do preço de reservatório em função do volume (Figura 4). Os custos do material hidráulico $(\mathrm{CMH})$ e da mão de obra (CMO) estão apresentados nas Tabelas 2, 3 e 4, tendo como fonte o mercado de Rio Branco.

Persp. Online: exatas \& eng., Campos dos Goytacazes, 17 (07) 12 - 24 - 2017

seer.perspectivasonline.com.br 


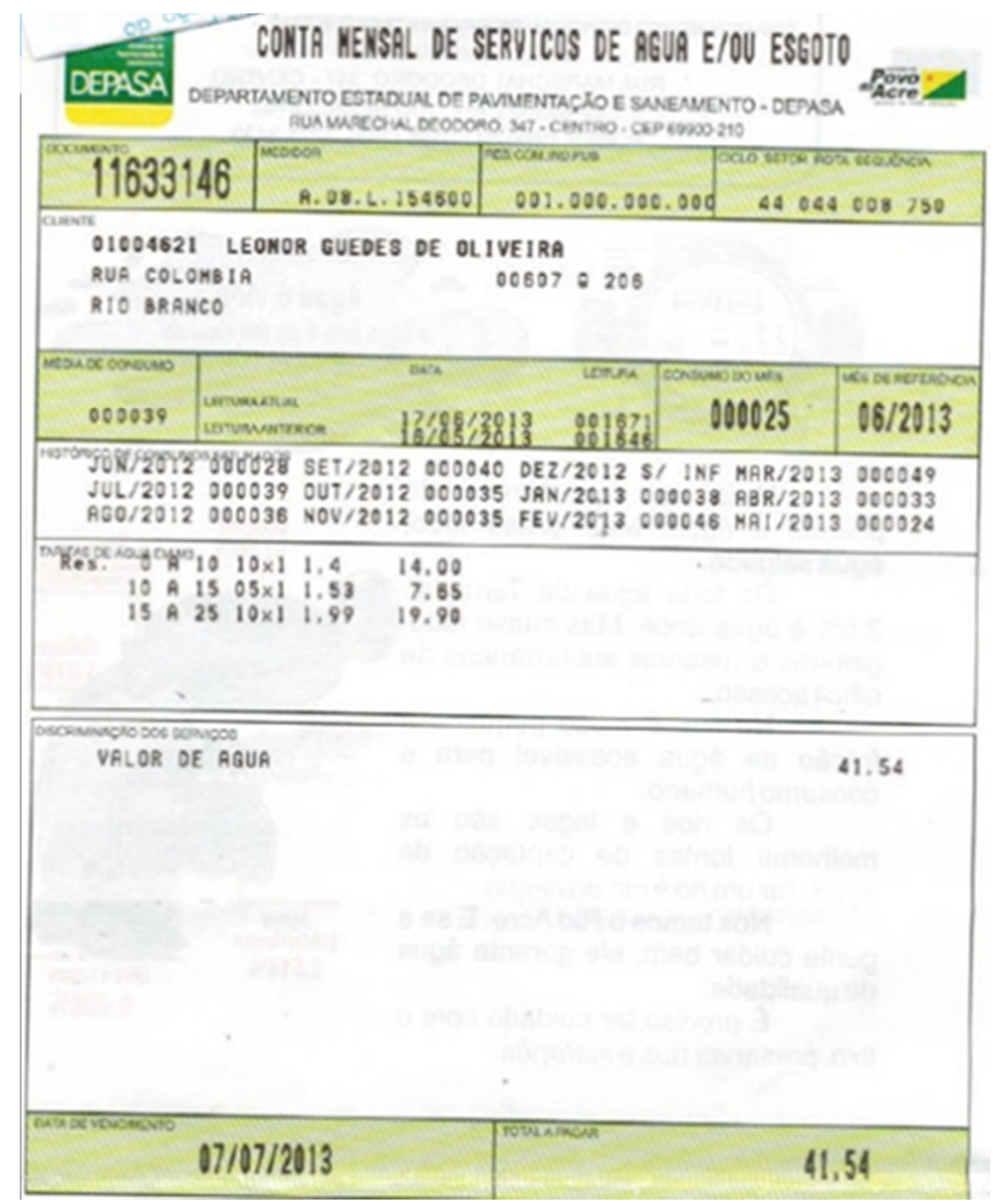

Figura 3: Conta de água DEPASA com consumo igual ao proposto no estudo

Persp. Online: exatas \& eng., Campos dos Goytacazes, 17 (07) 12 - 24 - 2017

seer.perspectivasonline.com.br 


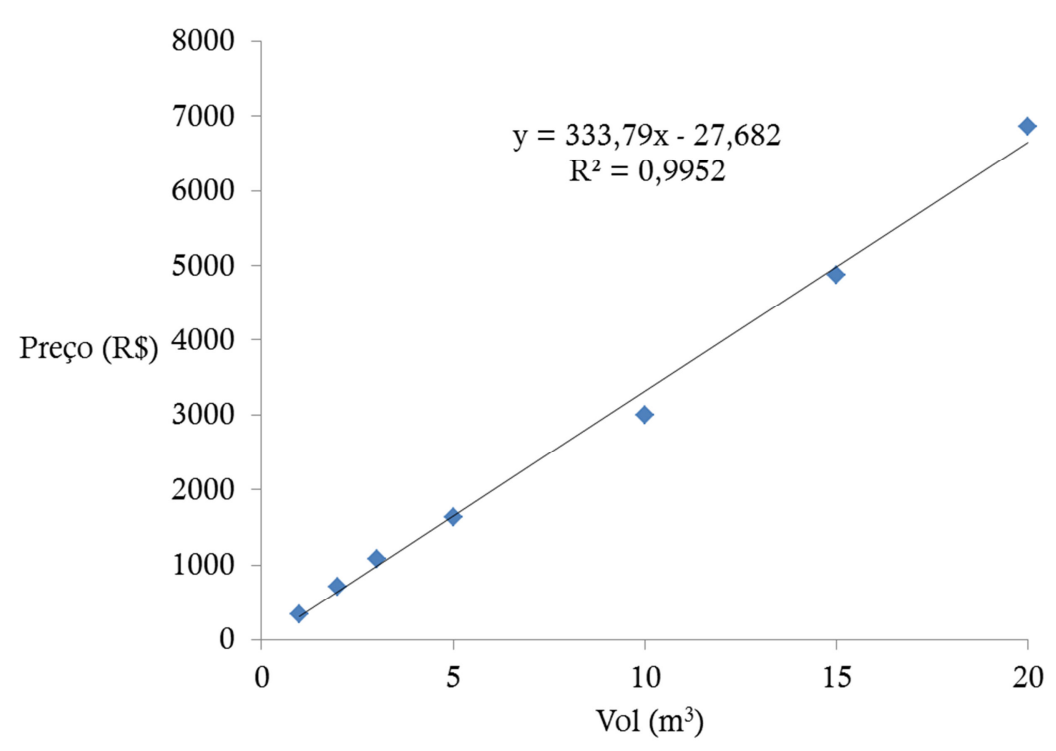

Figura 4: Variação do preço de reservatório de polietileno em função do volume

Tabela 2: Materiais e custo para montagem do filtro grosseiro de descarte

\begin{tabular}{|l|c|c|c|}
\hline Item & Und & Qtde & Preço (R\$) \\
\hline Tubo PVC - DN 100mm & $\mathrm{m}$ & 01 & 9,29 \\
\hline Tela mosquiteiro com proteção UV & $\mathrm{m}$ & 01 & 2,38 \\
\hline Adesivo para PVC & und & 01 & 1,51 \\
\hline Lixas n $\mathbf{6 0}$ e $\mathbf{1 2 0}$ & und & 02 & 1,20 \\
\hline Durepox & und & 01 & 2,08 \\
\hline Tinta Esmalte & L & 0,25 & 5,09 \\
\hline Pincel $\mathbf{n}^{0} \mathbf{1 0}$ & und & 01 & 2,00 \\
\hline TOTAL & & & 23,55 \\
\hline
\end{tabular}

Tabela 3: Materiais e custo do separador das primeiras águas da chuva

\begin{tabular}{|l|c|c|c|}
\hline Item & Und & Qtde & Preço (R\$) \\
\hline Tubo PVC - DN 75mm & m & 01 & 7,67 \\
Tê PVC - DN 75mm & und & 01 & 6,08 \\
\hline Anel de borracha Esgoto - DN 75mm & und & 03 & 3,54 \\
\hline Cap PVC Esgoto - DN 75mm & und & 01 & 4,22 \\
\hline Redução roscável de 1 1/4" x 1" & und & 01 & 1,85 \\
\hline Adaptador para válvula de tanque de 1 1/4"x40mm & und & 01 & 1,13 \\
Cap soldável de 40mm & und & 01 & 1,28 \\
\hline TOTAL & & & 25,77
\end{tabular}

Persp. Online: exatas \& eng., Campos dos Goytacazes, 17 (07) 12 - 24 - 2017 seer.perspectivasonline.com.br 
Tabela 4: Materiais e custo do sistema de captação de água pluvial

\begin{tabular}{|l|c|c|c|c|} 
& Und & Qtde & Preço (R\$) & Total (R\$) \\
\hline Sifão ladrão - $\mathbf{1 0 0} \mathbf{~ m m}$ & und & 01 & 353,44 & 353,44 \\
\hline $\begin{array}{l}\text { Freio d'água - 100 mm } \\
\text { Separador das primeiras águas }\end{array}$ & und & 01 & 154,11 & 154,11 \\
\hline da chuva & und & 01 & 25,77 & 25,77 \\
\hline $\begin{array}{l}\text { Filtro grosseiro de descarte } \\
\text { Mão-de-obra - Encanador }\end{array}$ & und & 01 & 23,55 & 23,55 \\
\hline Total & h & 16 & 10,00 & 160,00 \\
\hline
\end{tabular}

\section{RESULTADOS E DISCUSSÃO}

\subsection{Parâmetros de projeto}

Na Tabela 5, são apresentados os parâmetros de projeto calculados, conforme discutido anteriormente.

Tabela 5: Parâmetros utilizados no projeto do sistema de captação

\begin{tabular}{|c|c|c|c|c|c|c|}
\hline $\begin{array}{c}\text { Chuva } \\
(\mathbf{m m})\end{array}$ & $\begin{array}{c}\text { DAM } \\
\left(\mathbf{m}^{3} / \mathbf{m} \hat{\mathbf{s}}\right)\end{array}$ & $\begin{array}{c}\text { A } \\
\left(\mathbf{m}^{2}\right)\end{array}$ & $\begin{array}{c}\text { V } \\
\left(\mathbf{m}^{3}\right)\end{array}$ & \multicolumn{2}{|c|}{ Calhas } & \multicolumn{2}{c|}{$\begin{array}{c}\text { Condutos } \\
(\mathbf{m})\end{array}$} & $\mathbf{L}(\mathbf{m})$ & \begin{tabular}{c} 
Verticais \\
\hline 78,74
\end{tabular} & 7,93 & 241,20 & 15,19 & 0,10 & 0,20 & $\begin{array}{c}4 \text { de } 100 \text { mm de } \\
\text { diâmetro }\end{array}$ \\
\hline
\end{tabular}

Aplicando-se o método de Rippl aos valores analisados anteriormente, têm-se os resultados apresentados na Tabela 6, na qual (D-Q) ac. é a diferença acumulada entre a demanda do sistema e o volume de chuva aproveitável. Destaca-se da Tabela 6, o resultado da Demanda de Água Média para fins não potáveis, a qual, considerando os 5 habitantes da casa, é de $52,87 \mathrm{~L} / \mathrm{dia} / \mathrm{h}$ abitante. Esse valor é menor que os valores encontrados por Ghisi et al. (2006), que determinaram um valor médio entre 100 e $150 \mathrm{~L} /$ dia/habitante. Já Flores et al. (2012) determinaram uma demanda média de 222 a 260 L/dia/habitante. Observa-se que o valor encontrado no presente estudo é menor que os valores dos estudos supracitados. Entretanto, esses estudos determinaram o uso da água da chuva para fins potáveis e não potáveis.

Persp. Online: exatas \& eng., Campos dos Goytacazes, 17 (07) 12 - 24 - 2017 seer.perspectivasonline.com.br 
Tabela 6: Dimensionamento do reservatório através do método de Rippl

\begin{tabular}{|c|c|c|c|c|c|c|c|}
\hline MESES & $\mathbf{P}(\mathbf{m m})$ & $\mathbf{D}\left(\mathbf{m}^{3}\right)$ & $\mathbf{A}\left(\mathbf{m}^{2}\right)$ & $\mathbf{C}(-)$ & $\mathbf{Q}\left(\mathbf{m}^{3}\right)$ & $\mathbf{D}-\mathbf{Q}\left(\mathbf{m}^{3}\right)$ & $(\mathbf{D}-\mathbf{Q})_{\mathbf{a c} .}\left(\mathbf{m}^{3}\right)$ \\
\hline Jan & 278,20 & 7,93 & 241,20 & 0,90 & 60,39 & $-52,46$ & \\
Fev & 287,70 & 7,93 & 241,20 & 0,90 & 62,45 & $-54,52$ & \\
Mar & 256,70 & 7,93 & 241,20 & 0,90 & 55,72 & $-47,79$ & \\
Abr & 186,80 & 7,93 & 241,20 & 0,90 & 40,55 & $-32,62$ & \\
Mai & 97,20 & 7,93 & 241,20 & 0,90 & 21,10 & $-13,17$ & \\
Jun & 30,60 & 7,93 & 241,20 & 0,90 & 6,64 & 1,29 & 1,29 \\
Jul & 36,10 & 7,93 & 241,20 & 0,90 & 7,84 & 0,09 & 1,38 \\
Ago & 46,30 & 7,93 & 241,20 & 0,90 & 10,05 & $-2,12$ & \\
Set & 89,30 & 7,93 & 241,20 & 0,90 & 19,39 & $-11,46$ & \\
Out & 153,50 & 7,93 & 241,20 & 0,90 & 33,32 & $-25,39$ & \\
Nov & 206,70 & 7,93 & 241,20 & 0,90 & 44,87 & $-36,94$ & \\
Dez & 249,20 & 7,93 & 241,20 & 0,90 & 54,10 & $-46,17$ & \\
TOTAL & 1918,30 & 95,16 & & & 416,42 & $-321,26$ & \\
\hline
\end{tabular}

Baseando-se na Tabela 6, a diferença acumulada entre D e Q só é positiva nos meses de junho e julho, representando que nesses meses a água da chuva, no pior caso, que é julho, atenderá, ainda, a aproximadamente $80 \%$ da demanda da edificação para fins não potáveis de água. Observa-se também que os meses de junho e julho são característicos de estiagem em Rio Branco (Figura 2). Assim, optou-se pela utilização de um reservatório com a capacidade de armazenamento superior a demanda, ou seja, de $8,00 \mathrm{~m}^{3}$.

\subsection{Tempo de retorno}

Após o dimensionamento do reservatório, buscou-se analisar o sistema de captação de água de chuva do ponto de vista financeiro, estimando-se o tempo de retorno do investimento. Nesse caso, foi observado um problema de otimização, tendo como função objetivo a minimizar, o tempo de retorno do investimento (TR - Eq. 9); variável principal, o NPE (Número de Pessoas da Edifícação); e restrição, o volume de água captada. Essa otimização, justifica-se, pois o TR é função do custo do sistema (CS - Eq. 8), principalmente, do custo do reservatório; o qual é função da demanda de água mensal (DAM - Eq. 1). Na Figura 5, é mostrado como o TR comportou-se em função do NPE, considerando-se as características da unidade residencial analisada. Pode-se observar que o TR mínimo seria de 24 anos, se na casa habitassem 8 pessoas. O TR diminui até 8 pessoas, pois o consumo de água aumenta, aumentando a economia em relação ao que seria pago à concessionária. Entretanto, a partir de 8 pessoas, apesar do consumo continuar aumentando, o custo do sistema, principalmente, o custo do reservatório passa a ser mais importante, aumentando com isso o tempo de retorno. Para o estudo de caso em questão, 5 pessoas habitando a casa, tem-se um tempo de retorno mais alto para o investimento, ou seja, 27,1 anos.

Persp. Online: exatas \& eng., Campos dos Goytacazes, 17 (07) 12 - 24 - 2017 seer.perspectivasonline.com.br 


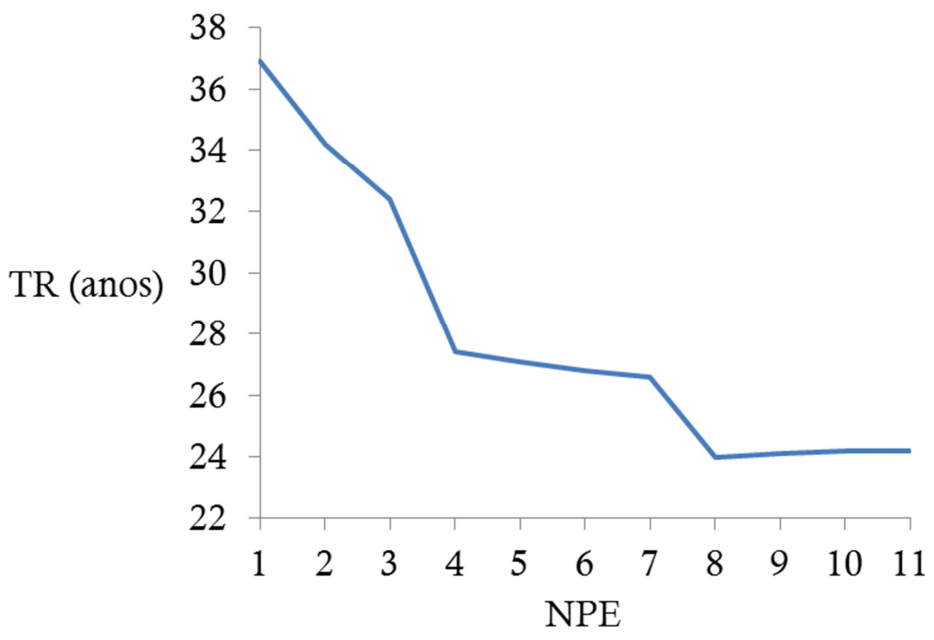

Figura 5: Tempo de retorno $x$ número de habitantes da edificação (Rio Branco-AC)

Esse tempo de retorno pode ser considerado alto, entretanto, observa-se que o valor da tarifa em Rio Branco-AC é baixo, quando comparado, por exemplo, à Belém-PA, igual a $\mathrm{R} \$ 2,68$ para a mesma faixa de consumo considerada no estudo de caso. Informação extraída do site da COSANPA Companhia de Saneamento do Pará (http://200.178.173.137/index.php/taxas). Assim, alterando-se apenas essa variável na análise, tem-se a Figura 6, com um tempo de retorno mínimo de 17,9 anos, também para 8 pessoas habitando a casa, e para 5 pessoas um tempo de retorno de 20,1 anos. Esses tempos estão abaixo dos tempos determinados para Rio Branco-AC, mostrando que o valor da tarifa é um fator determinante para o tempo de retorno do investimento do sistema de captação de água da chuva.

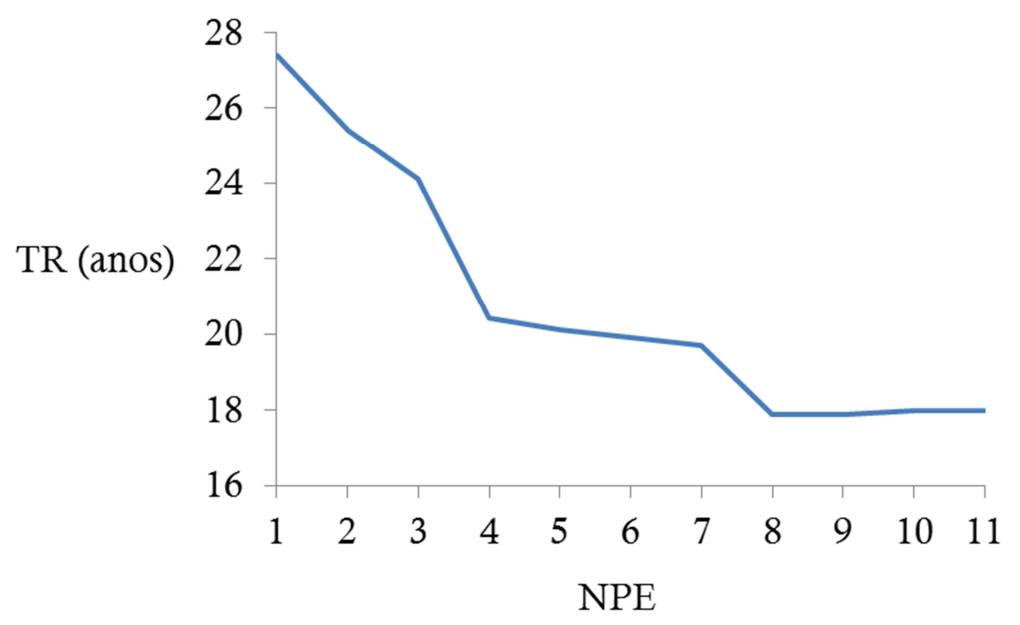

Figura 6: Tempo de retorno $x$ número de habitantes da edificação (Belém-PA) 


\section{CONCLUSÃO}

O sistema unifamiliar de captação de água da chuva para fins não potáveis diminuiria em 7,93 $\mathrm{m}^{3} \mathrm{o}$ volume de água tratada utilizada para descarga de vasos, lavagem de pisos, carros, roupas, rega de jardim entre outros. Isso geraria uma economia de água tratada na cidade, dando margem para o governo municipal ampliar o sistema de distribuição, garantindo o acesso à água potável para mais munícipes. Além desses benefícios, o sistema diminuiria problemas de drenagem urbana, retendo parte da água que escoaria pelas ruas e galerias, reduzindo assim o risco de enchentes. Entretanto, o tempo de retorno do investimento mostrou-se inviável. Um dos fatores que pode explicar a inviabilidade financeira é o baixo preço cobrado pela água no município de Rio Branco, um dos menores do país. O exemplo de Belém mostrou um valor maior da tarifa e um tempo de retorno menor, motivando estudos mais aprofundados da questão do aproveitamento de água de chuva para fins não potáveis.

\section{BIBLIOGRAFIA}

ABNT - ASSOCIAÇÃO BRASILEIRA DE NORMAS TÉCNICAS - Instalações prediais de agua pluvial: NBR 10844. Rio de Janeiro. 1989.

ABNT - ASSOCIAÇÃO BRASILEIRA DE NORMAS TÉCNICAS - Água de chuva aproveitamento de coberturas em áreas urbanas para fins não potáveis: NBR-15527. Rio de Janeiro, 2007.

ANNECCHINI, K.P.V. Aproveitamento da água da chuva para fins não potáveis na cidade de VitóriaES (dissertação). Vitória (ES): Universidade Federal do Espírito Santo; 2005. 150 p.

AZEVEDO NETTO, J.M.; FERNANDEZ, M.F.Y.; ARAUJO, R.; ITO, A.E. Manual de Hidráulica. 8 ed. São Paulo: Edgard Blücher, 1998. 160 p.

BOTELHO, M.H.C. \& RIBEIRO Jr., G.A. Instalações Hidráulicas Prediais Feitas para Durar. Usando Tubos de PVC. São Paulo: ProEditores, 1998. 238 p.

CAMPISANO, A.; MODICA, C. Optimal sizing of storage tanks for domestic rainwater harvesting in Sicily. Resources, Conservation and Recycling, v. 63, p. 9-16, 2012. Disponível em: $<$ http://dx.doi.org/10.1016/j.resconrec.2012.03.007>. Acesso em 08 de março de 2017.

EROKSUZ, E.; RAHMAN, A. Resources, Conservation and Recycling Rainwater tanks in multi-unit buildings $\square$ : A case study for three Australian cities. Resources, Conservation and Recycling, v. 54, n. 12, p. 1449-1452, 2010. Disponível em: <http://dx.doi.org/10.1016/j.resconrec.2010.06.010>. Acesso em 08 de março de 2017.

FEITOSA, N.B. \& FILHO, C.F.M. Abastecimento de água no meio rural. Disponível em: $<$ http://www.dec.ufcg.edu.br/saneamento/A0.html>. Acesso em 18 de fevereiro de 2013.

FENDRICH, R \& OLIYNIK, R. Manual de utilização das águas pluviais: 100 maneiras práticas. Curitiba: Livraria do Chain, 2002. 167 p.

Persp. Online: exatas \& eng., Campos dos Goytacazes, 17 (07) 12 - 24 - 2017 seer.perspectivasonline.com.br 
FLORES, R. A.; MENDES, R. L. R.; OLIVEIRA, D. R. C.; COSTA, T. C. D.; VELOSO, N. S. L. Potencial de captação de água de chuva para abastecimento: o caso da cidade de Belém (PA, Brasil). Estudos Tecnológicos em Engenharia, v. 8, n. 2, p. 69-80, 2012.

GHIMIRE, S. R.; JOHNSTON, J. M. Ecohydrology \& Hydrobiology Impacts of domestic and agricultural rainwater harvesting systems on watershed hydrology $\square$ : A case study in the AlbemarlePamlico river basins ( USA ). Integrative Medicine Research, v. 13, n. 2, p. 159-171, 2013. Disponível em: <http://dx.doi.org/10.1016/j.ecohyd.2013.03.007>. Acesso em 08 de março de 2017.

GHISI, E.; Montibeller, A; Schmidt, R., W. Potencial for potable water savings by using Rainwater: An analysis over 62 cities in Southern Brazil. Building and environment, v. 41, n. 2, p. 204-210, 2006. KÖNIG, K.W. The Rainwater Technology Handbook - Rainharvesting in Building. Fundamentals, practical aspects, outlook. WILO-Brain. Dortmund. Germany. 2001. 143 p.

MUNDT, R.D.; NOGUEIRA, C.U.; NOGUEIRA, H.M.C.M.; FANTINEL, A.L.; CECONI, C.A.; LEAL, L. 2013. Aproveitamento da água da chuva para lavagem de máquinas. $2^{\circ}$ fórum internacional ecoinovar. Disponível em: <http://ecoinovar.com.br/cd2013/arquivos/resumos/ECO158.pdf $>$. Acesso em: 25 de dezembro de 2014.

TOMAZ, P. Aproveitamento de água de chuva de cobertura em área urbana para fins não potáveis. 2009. Disponível em: <http://www.pliniotomaz.com.br/downloads/livros/livro_con servacao/capitulo8.pdf $>$. Acesso em: 05 de setembro de 2014.

ZHU, K.; ZHANG, L.; HART, W.; LIU, M.; CHEN, H. Quality issues in harvested rainwater in arid and semi-arid Loess Plateau of northern China. Journal of Arid Environments, v. 57, n. 4, p. 487-505, 2004.

Persp. Online: exatas \& eng., Campos dos Goytacazes, 17 (07) 12 - 24 - 2017 seer.perspectivasonline.com.br 